\title{
A Design and Implementation of Web-Based Project-Based Learning Support Systems
}

\author{
Hyosook Jung ${ }^{1}$, Woochun Jun ${ }^{2}$ and Le Gruenwald ${ }^{3}$ \\ ${ }^{1}$ Yang-dong Elementary School, Seoul, Korea \\ E-mail : est0718@chollian.net \\ ${ }^{2}$ Dept of Computer Education, Seoul National Univ. of Education, Seoul, Korea \\ E-mail :wocjun@ns.seoul-e.ac.kr \\ ${ }^{3}$ School of Computer Science, Univ. of Oklahoma, Norman, OK 73069, USA \\ E-mail : ggruenwald@ou.edu
}

\begin{abstract}
The use of the Web (World Wide Web) has had many positive effects on education. It overcomes time and space limitations in traditional schools. Teachers and students are now using the Web to access vast amounts of information and resources in the cyberspace. Also, learning via the Web enables both synchronous and asynchronous communication. Despite of many benefits of the Web, it may weaken students' motivation due to lack of face-to-face communication. In this paper, we provide a learning model called Web Project Learning, which is based on theprinciples of contructivism, to provide motivation and collaborative learning for students in the Web environment. The model is based on the Project-Based Learning model and is revised for use on the Web. The model can also encourage the participation of parentsas well as students, and be applied to any subject. We implement our model and show that it can be applied for environmental education as an instance.
\end{abstract}

\section{Introduction}

Recent advances in the Web have rapidly changed our life in various ways. These advances provide new ways for people to communicate on a global scale and assess vast amounts of information. The Web provides educators with opportunities to implement a range of new teaching and learning practices, which redefine classroom- 
learning experiences. The Web enables a so-called WBI (Web-Based Instruction) system as a teaching aid. The WBI system, which integrates a hypertext information network with communication and collaborative tools, presents two important innovative features: first, it provides specific tools to manipulate the multimedia information contents of the Web pages; second, authorized users can modify the information network in the system $[1,2,3]$.

Despite of many benefits of the Web in the learning process, it may weaken students' motivation in the cyberspace because of lack of face-to-face communication. The lack of student control is also considered one of the drawbacks of WBI unless a teacher keeps the students working towards its goal. As teachers' influence decreases, students may become disengaged. Thus, students are unable to concentrate their thoughts upon their work. It is reported that about $30 \%-50 \%$ of students who have started a distance education course dropped out before the end of the course [4]. To make the learning process effective, we must motivate students to be engaged in the learning activities. A learning experience where the learner must contribute to an activity is called active engagement, while a learning experience where the learner is mainly a recipient of information is called passive engagement [5]. When a form of engagement is engrossed by a learning activity, the learner is focused and attentive, and becomes captured and committed to the task at hand.

Teachers have found that working on projects is an engaging activity with a large potential for facilitating learning [6]. Project work provides a context for taking initiative and assuming responsibility, making decisions and choices, and pursuing interests. The Project-Based Learning Model also can be used to enrich the curriculum, strengthen Internet skills, and provide integrated and thematic learning opportunities [7,8].

In this paper, we present the Web-based Project-Based Learning Model for the Web environment. It is based on the existing Project-Based Learning Model, but it also can motivate students and provide real life contexts for successful collaborative learning in various ways on the Web. Our model also adopts the principles of constructivism so that both collaborative learning and self-learning are emphasized. 
We design the model for the Web environment and implement for classroom use. The model can be applied to any subject. We show that the model can be applied for environmental education as an instance.

This paper is organized as follows. In Section 2, we present constructivism and Project-Based Learning on which our model is based. Our proposed Web-Based Project-Based Learning Model is introduced in Section 3. Section 4 describes how the proposed model is implemented. Finally, we give conclusions and further research issues in Section 5.

\section{Background}

\subsection{Constructivism}

Constructivism is an idea that has been embraced by educational researchers and is defined as follows [5]. Each individual must create anything he or she knows using his or her own mind. There are two basic sources of raw material from which new knowledge is created. One is already known thought, and the other is new information available from the senses. New information combined with existing ideas can create modifications to current improvements. On reflection, an idea that we must all create in our own knowledge seems obvious. The value of this idea is in its corollaries. The first of these is that the more one understands, the more readily one can learn new ideas. Or conversely, the less one knows, the harder one can learn new things. The second is that a good learning situation enables us to try out ideas repeatedly, making modifications, seeing what works and what does not, and using this experience to refine our conceptions. The third is that the learner must be an active participant, who is mixing, matching, and trying ideas together. It is not enough to just allow ideas to enter our mind; they must be integrated into existing structures and thought patterns. And this means that for learning to occur, we must be motivated to become engaged in the learning activities. 


\subsection{Project-Based Learning}

A project is an in-depth investigation if a topic worth learning more about. The investigation is usually undertaken by a small group of students within a class, sometimes by a whole class, and occasionally by an individual child. The key feature of a project is that it is a research effort deliberately focused on finding answers to questions about a topic posed either by the children, teacher, or the teacher working with the children. The goal of a project is to learn more about the topic rather than to seek the right answers to questions posed by the teacher [7].

Project-Based Learning refers to a set of teaching strategies which enable teachers to guide children through in-depth studies of real-world topics. The ProjectBased Learning is not unstructured. There is a complex but flexible framework with features that characterize the teaching-learning interactions. When teachers imp lement Project-Based Learning successfully, students can be highly motivated, feel actively involved in their own learning, and produce work of a high quality [9].

The values of Project-Based Learning include the following:

a). Project-Based Learning is a model for classroom activities that shift away from the traditional classroom practices of short, isolated, teacher-centered lessons, and instead, emphasizes learning activities that are long-term, interdisciplinary, studentcentered, and integrated with real-world issues and practices.

b). One immediate benefit of practicing Project-Based Learning is the unique way that can motivate students by engaging them in their own learning. Project-Based Learning provides opportunities for students to pursue their own interests, questions and make decisions about how they will find answers and solve problems.

c). Project-Based Learning also provides opportunities for interdisciplinary learning. Students apply and integrate the content of different subject areas at authentic moments in the production process, instead of in isolation or in an artificial setting. In the classroom, Project-Based Learning provides many unique opportunities for teachers to build relationship with students. Teachers may fill the varied roles of coach, facilitator, and co-learner. Finished products, plans, drafts, and prototypes all 
make excellent "conversation pieces" around which teachers and students can discuss the learning that is taking place.

d) In the school and beyond, Project-Based Learning also provides opportunities for teachers to build relationships with each other and with those in the larger community. Student' work, which includes documentation of the learning process as well as the students' final projects, can be shared with other teachers, parents, mentors, and the business community who all have a stake in the students' education [10].

\section{Design of a Web-Based Project-Based Learning Model}

\subsection{Web-Based Project-Based Learning}

One of the most promising ways the Internet is being utilized in school is to have students participate in global collaborative Internet projects. In this section, we propose a learning model called the Web-Based Project-Based Learning (hereinafter called 'Web Project Learning') for the Web environment. The Web Project Learning is defined as problem-oriented learning within the framework of a small group, a whole class, or an individual project and using web support for the project activities. The model is based on the Project-Based Learning Model we mentioned earlier in Section 2.2, but it can motivate students to participate in the project voluntarily and actively. It also provides real-life contexts for successful collaborative learning [5].

In teaching, the Web fits very well with the Project-Based Learning Model. The Web can be an organizer, a research tool, a ready source of data, a means for people to communicate with each other, and a repository for artifacts. Because the Web is a part of the real world, and artifacts on the Web can readily be placed in the world beyond school, projects have a scope for authenticity not usually found in the school environment.

The Web Project Learning can motivate both students and teachers as it provides an appealing way for students to gain Internet skills while being engaged in regular classroom activities. Through the projects, students are encouraged to develop a range 
of skills relating to reading, writing and researching as well as developing their abilities in selecting, presenting and communicating information. When students work on their project, they strengthen research and organization skills while being responsible and self-motivated all skills they will need in the information age. Students feel a sense of engagement because they work with topics that they have chosen for themselves.

\subsection{Web-Based Project-Based Learning Model}

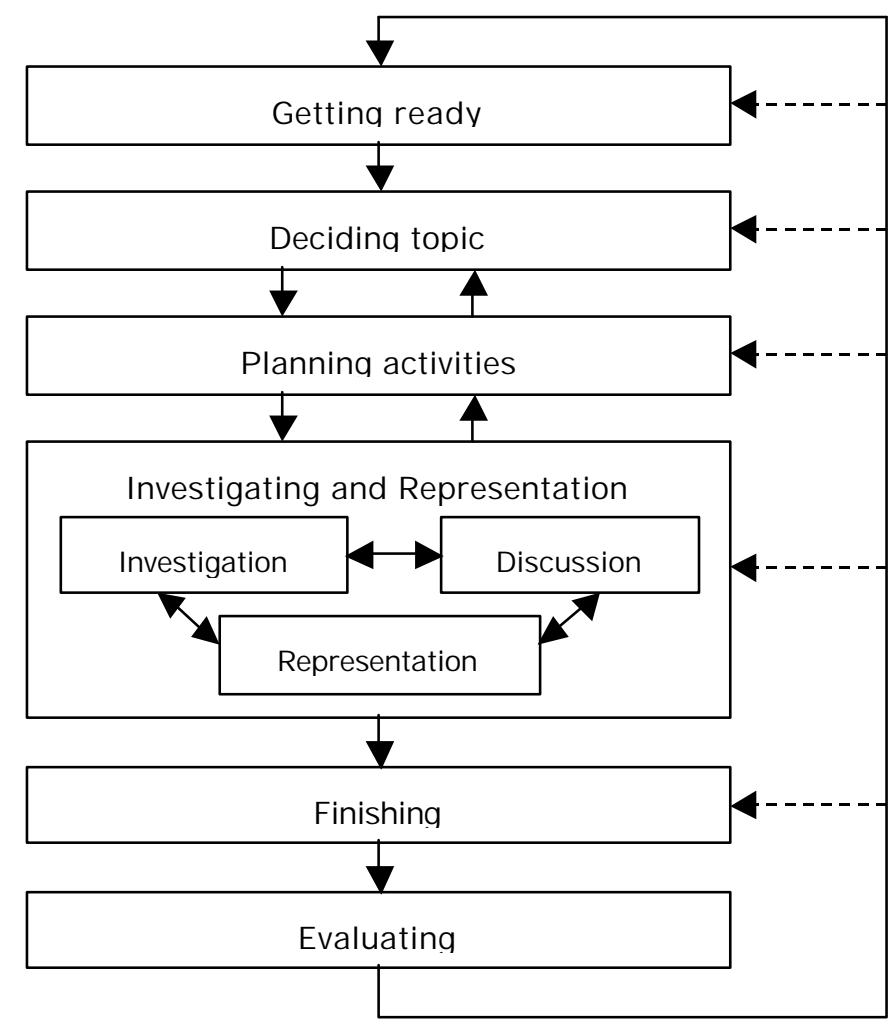

Fig. 1. Web Project Learning Model

The Web Project Learning Model is divided into the following six phases instead of only three phases, which are Getting Started, Field Work and Culminating and 
Debriefing Events, as in the existing Project-Based Learning models [7,8,9].

1. Getting ready. First of all, a teacher designs a project outline. The outline's purpose is to provide the information necessary for students to envision their own project within the scope of the outline, and provide resources to help them carry it out. It must provide goals of the whole project for students, and sufficient guidance for students to choose appropriate questions, activities, and products. The outline will be mainly read and used by students. A teacher analyzes and integrates curriculum, lists questions, researches Web sites or resources that can be helpful for students to investigate during the course of the project, and post on the Web.

2. Deciding topic. Students read the Web Project outline and search for resources. References to resources consist of URLs to relevant Web materials so that students can be directed immediately to high quality materials that match the project needs. Students recall their own past experiences related to the project, make topic map and exchange their ideas. During preliminary learning, the students decide subtopics of the project for themselves.

3. Planning activities. Students work on individual student projects, in-class collaborative projects, or class-to-class projects. They determine the activities and events that will take place at each stage of their subtopics, plan appropriate timelines for all their subtopics, and post on the Web. If they work on a collaborative learning project, each team member must have specific roles and responsibilities. Teachers communicate contents of project planning to parents so that they can help and support their children work on the projects.

4. Investigating and Representation. Investigation includes activities such as interviewing experts through e-mail, investigating Web sites, and sharing exchange new experience and knowledge and doing a survey through the Web. In addition, it includes observations, experiments and field trips. Discussion includes both synchronous and asynchronous communication through the chatting or bulletin board system. Representation includes drawing, painting, writing, math diagrams, maps, etc. to represent new learning. Regularly, parents report the children's condition to 
teachers.

5. Finishing. Students produce reports, presentations, Web pages, images, pictures, construction, etc. as a result of the activity, share their end products, and celebrate them on the Web. Teachers have students write down their reflections on the project and things to remember for next time.

6. Evaluating. Teachers evaluate the whole process of the project and arrive at grades based on participation and products.

\section{Implementation of the Web-Based Project-Based Learning Supporting System}

The system is to make teachers and students carry out projects wherever and whenever they may work. It helps teachers and students begin developing an overall plan for managing their project. For Project-Based Learning to be ensured as studentcentered learning, the system must give students experience in planning for the project and in working in team or class, and have students create their assignments as form of HTML documents or reports. Normally the environmental education of elementary schools has to be authentic in that it is concerned with a rea-world situation or problem because of cognitive development process of students. Our model will be an alternative of environmental education in classroom As a result, we expect that students will recognize the importance of environmental protection and have motivation to practice environmental conservation.

In this paper, the system is implemented on a Windows NT 4.0 Server and subsequent IIS 4.0. We use database management based on SQL Server 7.0 and the HTML and ASP language for managing information. The overall requirements of hardware and software for the implementation are listed in Table 1. Our system is implemented in http://203.234.37.75/jung/frame.asp in Korean. Its English version will be available soon. 
Table 1. Development environment and tool

\begin{tabular}{|c|c|c|}
\hline \multirow{4}{*}{ Hardware } & Elements & Options \\
\cline { 2 - 3 } & CPU & Pentium II 333MHz \\
\cline { 2 - 3 } & RAM & $64 \mathrm{MB}$ \\
\hline \multirow{4}{*}{ Software } & Operating System & Windows NT 4.0 \\
\cline { 2 - 3 } & Web Server & IIS 4.0 \\
\cline { 2 - 3 } & Database Server & MS SQL Server 7.0 \\
\cline { 2 - 3 } & Brower & Internet Explorer 5.0 \\
\cline { 2 - 3 } & Programming Language & Active Server Page \\
\hline
\end{tabular}

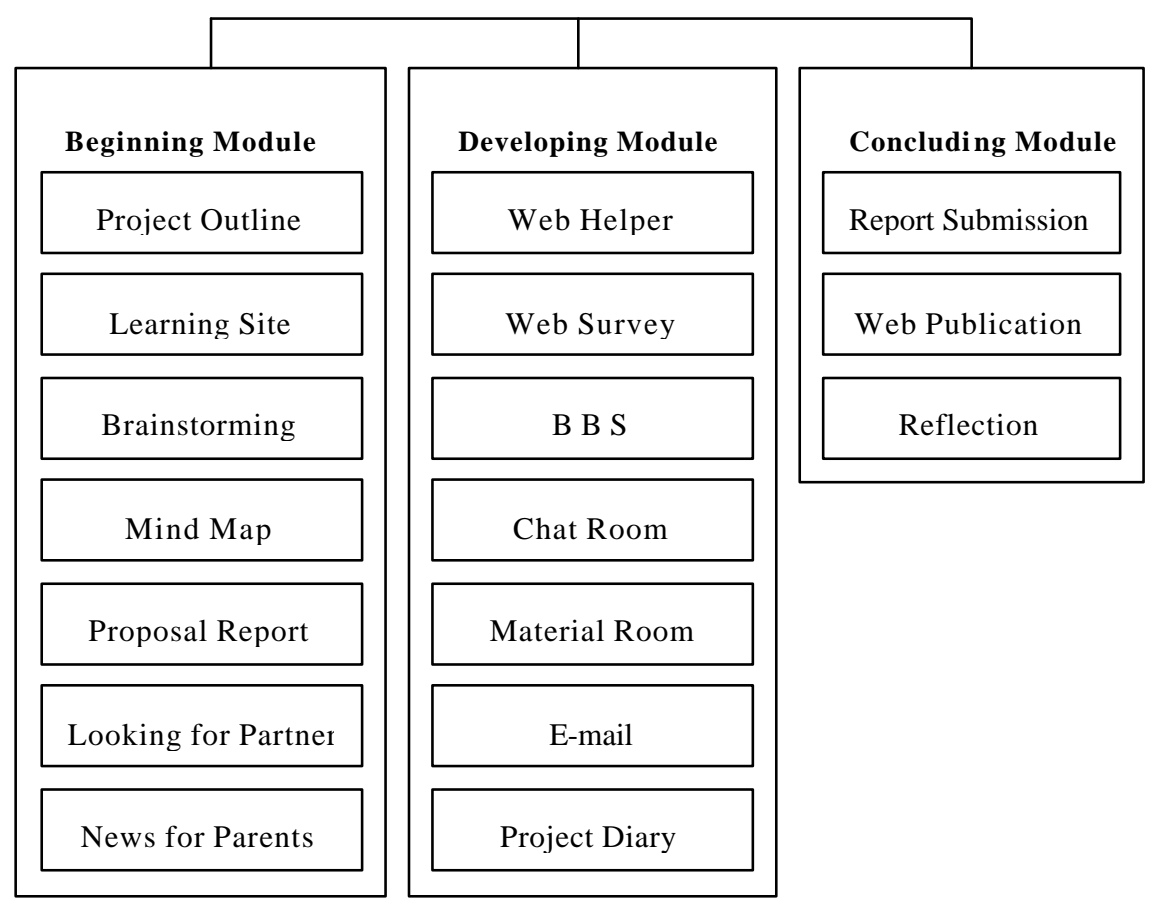

Fig. 2. The structure map of the system 


\subsection{Beginning}

The "Project outline" explains the project while "Learning site" is connected to useful Web resources within the project. Students explore the Web site in advance, propose what they wish to investigate through brainstorming, and make a mind map. Once a subtopic has been selected, students or small groups of students plan an appropriate timeline and activities for their project and show them to teachers and all their friends on the Web. If necessary, teachers or students can advertise to look for partners on the bulletin board system. Through news for parents, parents can understand the project planning their children will work on. Fig. 3 presents an example of a project outline form. A teacher completes the section of the project outline form and submits it. Information appearing on this form will appear on the Web. So students can read it and understand the central questions of their project, what they are going to do and what products they are going to produce.

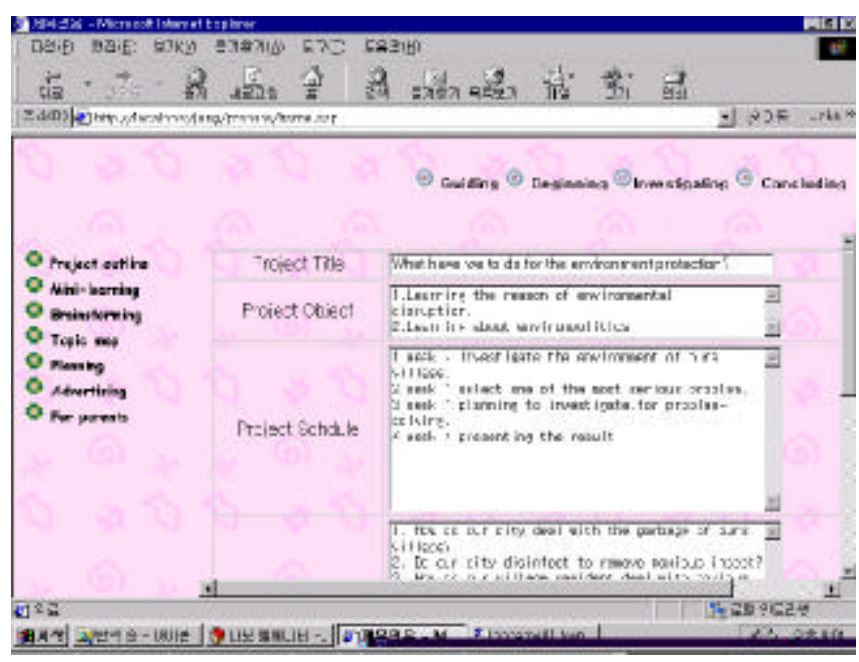

Fig.3. An example of a project outline form 


\subsection{Developing Module}

Students can use the Web in order to communicate with field experts about experience and knowledge of the topic and use email, chat room, or BBS (Bulletin Board System) to communicate with other people both individually and as a group. Also, they search for information on the Web, do a survey and represent the results, share resource and information on the material room. Project diary is parents' comments on children's work. Parents can appreciate the work in which their children are engaged. They may be able to contribute ideas for field experiences which the teachers may not have thought of, especially when parents can offer practical help in gaining access to a field site or relevant expert. Fig. 4. shows a main picture of the developing module. Two photos show students undertaking learning activities as teamwork.

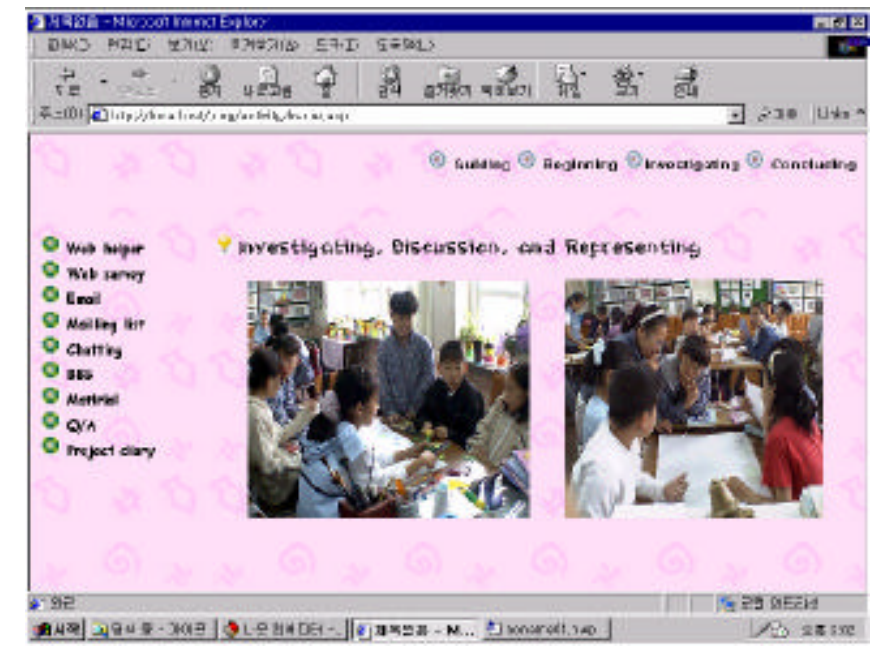

Fig. 4. Main picture of the developing module

\subsection{Concluding Module}

Students present reports of results in the form of Web pages, presentations, construction, document files, etc. to the entire class and discuss or write about 
suggested future improvements. Fig. 5 presents an example of a project report form. Students use this form to report the results of a project.

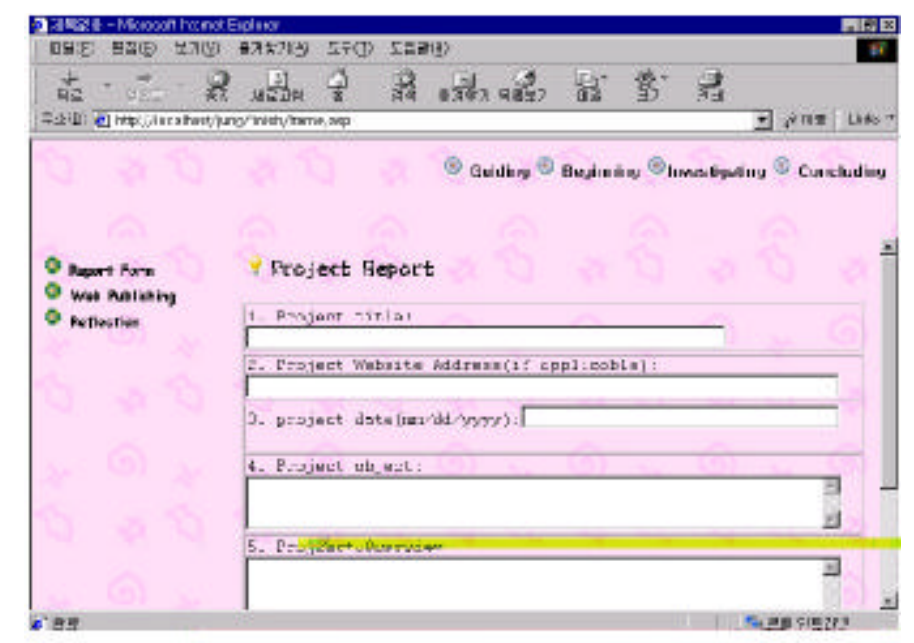

Fig. 5. An example of a project report form

\section{Conclusions and Further Work}

In this paper, we proposed a learning model called Web Project Learning to provide motivation and collaborative learning to students in the Web environment. We expect that students are concerned with the problems of their regional environments and investigate them when our learning model is applied to environmental education. Our model also encourages students to interchange their own peculiar environmental characteristics. Using the proposed model, students can strengthen research and organization skills while being responsible and self-motivated. As they gain learning experience for the pure joy of learning, their emotional interest, intrinsic motivation, and hunger for knowledge can also be increased. The students are immersed in an authentic learning environment while undertaking the project. Their activities encourage them to exercise life skills such as problem solving, communication and 
collaboration, making decisions, and using information technology. Also, parents are concerned about their children's development and thus will participate in and contribute to the project. As teachers examine the students' work and prepare the project, their own understanding of students' development is deepened.

Further research issues are as follows. At first, we need to develop evaluation criteria that we can post it on the Web to let students know how their projects will be evaluated. We will also need to conduct a study comparing the performance of students using our proposed model and that of students following traditional classroom teaching. Currently, various schemes to provide motivation on cyber education are somewhat subjective and depend on psychological effects $[11,12,13,14]$. As a result, we have to develop the various ways to provide motivation for students. In our earlier work [15], providing motivation on the Web was considered in terms of three categories, Student-to-Course Content relationship, Student-to-Teacher relationship, and Student-to-Student relationship. Currently we are refining the earlier work.

\section{Reference}

[1] Seryn, W. \& John, E. (1997), A case Study of communication technology within the elementary school, Australian Journal of Educational Technology, 13(2), $144-164$

[2] Giovanni, F. \& Rosella, C. (1999), A Web-Based Instruction System to support design activities in Architecture, Paper presented to AusWeb 99, Fifth Australian World Wide Web Conference.

[3] Mason, R. (1991), Moderating Educational Computer Conferencing in DEOSNEWS Vol. 1 No. 19.

[4] Richard, C \& Barbara L. M. (1997), The Role of motivation in Web-Based Instruction, Web-Based Instruction, 93-100,

[5] Marv, W. (2000), Learning with the Web, Paper presented to Korea Association of Educational Information \& Broadcasting, 2000, November, 7-36 
[6] Katz, L.G. and S.C. Chard. (1989), Engaging children's minds: the project approach, Norwood, NJ: Ablex.

[7] Katz, L. G. (1994), The Project Approach, ERIC Digest; EDO-PS-94_6, [Online] http://ericps.crc.uiuc.edu/eece/pubs/digests/1994/lk-pro94.html

[8] http://teacher.scholastic.com/professional/teachtech/usinginternet.htm

[9] http://www.project-approach.com/definition.htm

[10] http://pblmm.k12.ca.us/PBLGuide/WhyPBL.html

[11] P. Duchastel, "A Motivational Framework for Web-based Instruction”, in Web Based Instruction, edited by B. H. Khan, Educational Technology Publications, New Jersey, USA, 1997.

[12] E. Cho, "Distance Instruction”, The Journal of KIPS, Vol. 4, No. 3, May 1997, pp. $20-28$.

[13] Y. Son and K. Kim, "Evaluating Instructional Web Pages with Web Evaluation Model", Proceedings of the $4^{\text {th }}$ KAIE Winter Conference, 1999, pp. 320 - 328.

[14] S. Song, Providing Motivation in Web-Based Instruction, in Web-Based Instruction, edited I. Na, Educational Science Press, May 1999, Seoul, Korea.

[15] W. Jun and L. Gruenwald, “An Evaluation Model for Web-Based Instruction”, will appear in IEEE Trans. on Education, May issue, 2001. 